ment of the principal events in muscular contraction was put forward by A. Szent Györgyi, and provoked a vigorous discussion (see also p. 262).

The refinement of physical methods applicable to living organisms has progressed rapidly. Methods of measuring tissue fluid flow by radioactive helium, recording the contour of the heart by a precise radiographic and photo-electric method, continuous records of blood pressure in man by a condenser manometer, all provide powerful tools for work on the circulation. The clinical physiologists, A. Cournand, J. V. Warren, E. A. Stead, J. McMichael and E. P. Sharpey Schafer, using cardiac catheterization, have demonstrated the similarities as well as the differences in the behaviour of the circulation in man and in anæesthetized animals.

The nature of the proteins of muscle and of the nucleus and its chromosomes has continued to occupy much attention. The central nervous system also was the subject of a large number of papers; but there were no outstanding advances in any of these fields.

The Congress accepted an invitation to Copenhagen for the Eighteenth International Congress, to be held in 1950, under the presidency of Prof. August Krogh.

On the last day, the University of Oxford conferred degrees of Doctor of Science on Profs. C. H. Best, H. S. Gasser, B. A. Houssay, August Krogh and A. Szent Györgyi.

\section{GRASSLAND AND ANIMAL PRODUCTION}

$I^{\mathrm{N}}$ July 1937 the International Grassland Conference was held in Great Britain, and the delegates exam. ined closely the work and promise of the Aberystwyth nucleus, from which so much of the newer knowledge and philosophy of grassland management has spread. In the last week of June 1947, a further review of the activities of the Welsh Plant Breeding Station was made by members of the British Grassland Society and the Society of Animal Production at the first joint meeting of the two groups. This occasion, too, was given a minor international flavour by the representatives from countries overseas, who took the opportunity to refresh their contacts with workers in Britain; but, useful as this was, the greater significance of the meetings and visits lay in the interchanges of ideas and comments between those concerned on one hand with better grassland and, on the other, with better use of that grassland by the animal.

At first glance, there should be no divergence between the two aspects; clearly, however, there is. Moreover, there might appear to be a close parallel between the objectives of the animal husbandman and the agronomist : one aims to increase productivity by better nurture, better breeding, and a replacement of the less biologically efficient stock by those of greater and more reliable merit, the other at improving productivity of the plants by broadly similar means. Yet such a parallel would be deceptive as a representation of the past, and even present, courses of the two lines of endeavour.

During the last ten years great progress has been achieved in the development of plant-breeding methods and material. At all stages of the process, from the search for fresh material, its testing, experi- mental breeding, progeny-testing, and multiplication, to the treatment of seed, and the certification of stocks, as well as in the maintenance of proved stock plants or strains and in the trials of material from other sources in pure cultures and in mixtures, the techniques have advanced even under the difficulties occasioned by war-time shortages of personnel and equipment. The gardens and trial grounds of the Plant Breeding Station at Penglais, with the larger plots and field trials at Frongoch and the multiplication fields at Morfa Mawr, provided the background for a spectacular display by Prof. T. J. Jenkin and his colleagues of the use and application of the old and new methods-to the envy of the animal breeders, who, restricted by the numerical smallness, but physical largeness, of their material, have also to think in terms of populations.

The years of war have accelerated the spread of the selected Aberystwyth strains of grasses and of clovers into practical conditions of grassland establishment. The urge to increased production of British agriculture has given encouragement to ley farming, and the demand for seed of known origin has had repercussions in the seed trade, as well as on the administrative and routine activities of the staff of the Station. At the same time, the principles and methods of improving the swards of the higher and inherently poorer grazing lands, as developed at Llety-Evan-Hen and the Cahn Hill Improvement Scheme, have been given a wider extension to other hill areas, to the enhancement of sto $\mathrm{k}$ production, as was described by Mr. Moses Griffith and Prof. W. Ellison at the separate meeting of the Society of Animal Production. The prospect of the early discontinuation of the Cahn Hill work is regarded with concern by both Societies, the members of which recognize the important role of the hill farming areas in the maintenance of a healthy and balanced stockraising industry in Great Britain.

Though somewhat envious of the technical opportunities and material advantages offered to the plant breeders, the stock men were none the less comforted. They found themselves, for example, on familiar though not so clearly signposted country in noting such matters as the variation among the progeny from selected parents and strains, the differential responses of varieties and strains under a common environment and changed behaviour in other environments, the range in maturity, the effects of length of day on reproductive organs, the handiness of 'indicator' characters (but not of necessity their feasibility as measures of performance), change or 'degeneration' in the later generations of stocks grown on in other areas, or even the different potentialities and performances of 'pedigree' and 'commercial' strains. There should be much common ground here for future co-operation in study and discovery of principles, for example, in wedding the ecological approach to the genetical, to enlighten the limits of selection in one environment to meet the demands and suitabilities in another.

The present divergence of views occurs with regard to purpose and method. The emphasis in the grassland work appears, to the animal husbandman, to be on the sward, and its management to the benefit of the sward. The increased productivity of swards, as swards, which can emerge from suitable seeds mix tures, sown under favourable conditions of soils and cultivations, with appropriate fertilizer treatments and apt grazing and cutting, is clearly demonstrable and has, in fact, been often and well demonstrated. 
The possible marked extension of the grazing season and the expanded opportunities for conservation of the surplus product of highly valuable protein foodstuff affords hope of a greatly enhanced, even revolutionary, level of animal production. Sir George Stapledon, in a noteworthy address, suggested a ten-year plan for more livestock to utilize his envisaged 9 million acres of leys and 4 million acres of permanent grass against the present 10 million permanent and 3 million leys-and asked for guidance as to numbers, kinds and quality for this target. Yet he, adding his emphasis to that offered by many of the demonstrations, recognizes the extraordinary niceties of reaction of the plant strains and mixtures to all points of management, and implied doubts whether a suitable technique of testing the absolute value of the pastures can be derived unless they are grazed at different intensities of grazing, and admitted that at times, for suitable conditions of conservation of surplus growth, drastic treatment by cutting has to be adopted.

The main use of grassland is for grazing - but that platitude over-simplifies many of the real issues. Experimentally it may justify using the grazing animal to measure pasture productivity in terms of live-weight increase or milk yield, which terms achieve an apparent validity since they are involved in economic or practical returns. However, it has also been clearly shown that grazing in itself is a powerful factor in altering the composition and 'utility' of the grazed pastures. Pasture management has long been realized to involve control of the biotic factor, but from the animal physiologist's point of view the nature of this complex influence is by no means sufficiently understood for it to be used as anything more than a very general and indirect measure of productivity. This is especially the ease when there is a dearth of experimental evidence on the important question as to how far the very conditions of restraint, implied in using animals to graze small plots under trial conditions, themselves affect the animals' reactions, behaviour, growth, development and output, as of live-weight.

The ultimate purpose is to translate experimental results into farm practice. This introduces another set of, as yet, imponderable factors. The field is a unit only in so far as it is part of the farm; the grazing animal also is part of a herd or flock. For the farm as a whole-even for the country as a whole - the supply of winter feed is the limit to production; to widen this restriction, forage crops and conserved grassland in the form of silage or dried grass offer prospects of greater developmont. But a better and more efficient alternative in present circumstances, in Dr. John Hammond's view, might be to utilize the high production of the summer months for cheaper summer fattening, and to conserve and store the animal product rather than the grass. Again, the numbers of animals on a farm are relatively fixed over long periods; under practical conditions, especially in these days of self-contained dairy herds, the farmer cannot arrange the timing or intensity of grazing to meet those niceties of management which the grassland expert dictates as optima for the good of the sward. As Prof. W. C. Miller suggested, the complex situation of stocking and stock-management may require more complex mixtures of grazing constituents to provide pastures which can be practically mismanaged with safety, rather than a multiplicity of mixtures and treatments, each needing specific control to evoke their best response.
So long as conditions vary from farm to farm, field to field, and season to season, the principles of stock and grazing management must be allowed very flexible application. Even those of rotational grazing, with subdivision of the areas into smaller units, particularly in so far as it involves the human factor of judgment of pasture productivity, are not fully understood, as the plots at the College Farm at Nantcellan show. The formal and informal discussions at these meetings proved that a great deal of endeavour remains to be applied to the problems of the pastures we grow, the uses to which they can be put, and our methods of using them-and that any mutually exclusive interpretation of the results of experiment and observation by animal and grassland specialists is no longer admissible.

\section{J. E. NґCHOLS}

\section{THE RADIATIONS FROM THE EARTH'S ATMOSPHERE}

$\mathrm{N}$ the latitudes of London, Paris or Washington 1 the appearance of an aurora borealis is somewhat infrequent and finds few investigators prepared with equipment for detailed observation. Most of the work on the location and spectra of aurora has therefore been done at such places as Tromsø, which are within the main auroral belt : our knowledge of the phenomenon is mainly due to Størmer and Vegard, and their collaborators. The principal progress has been achieved in the present century, and especially in the last ten or fifteen years. It has only been rendered possible by the rapid general advances in physical techniques and equipment.

During the first quarter of this century, it began to be recognized that at all latitudes the night sky is appreciably luminous even in the absence of the moon. This effect is partly due to radiation from the stars, both those individually visible and those much more numerous stars too faint to be detected by the unaided vision; the zodiacal light, which is of the nature of scattered sunlight, also makes a contribution. But the major part of the luminescence originates in the atmosphere itself: its spectrum shows a complex set of emission lines and bands against a continuous background. The intensity is very low, so the observational work is extremely difficult. Slipher, who was among the first to study the spectrum of the night sky light, discovered that a permanent component of it is the famous green line previously known to be prominent in the auroral spectra. Rayleigh, who used characteristically simple methods, devised and carried out, partly with the aid of observers overseas, a many-sided programme of observations. By means of filters he distinguished three different spectral regions and studied their geographical distribution and their temporal variations. He even measured the absolute intensity of the green line: the number of photons he found to be emitted in a square centimetre column of atmosphere is about $2 \times 10^{8}$ per sec. This remarkable pioneer work gave results of lasting value.

The problem of the identification of the green line was solved by McLennan and his colleagues who, in the years 1925-27, showed that it arose from atomic oxygen and is due to what is called a forbidden transition-that is, one that violates the normal selection rules and is only possible because of their approximate nature. Now the emission of the green- 